\title{
AN EVALUATION OF THE FORGEABILITY OF DELTA PROCESSED UDIMET ${ }^{\circledR}$ ALLOY 718DP
}

\author{
T. Banik, S. O. Mancuso, and G. E. Maurer \\ Special Metals Corporation \\ Middle settlement Road \\ New Hartford, NY 13413
}

\begin{abstract}
Subscale hot compression testing was performed to evaluate the thermomechanical response of fine grained UDIMET alloy 718 and ultra-fine grained, delta-processed UDIMET alloy 718DP. Results were used to identify conversion parameters that could be used to produce a variety of billet and bar products made from a common buffer stock.

Compression testing of the delta processed fine grained product identified flow stresses that were lower than those measured for conventional fine grain material. The delta processed material also had better grain size control throughout the hot working temperatures from $940-1024^{\circ} \mathrm{C}$. Differences were a result of the residual spheroidized delta phase in UDIMET alloy 718DP which helped to maintain very fine recrystallized grain sizes up to hot working times and temperatures at which the delta phase was completely solutioned. The lower flow stresses of UDIMET alloy $718 \mathrm{DP}$ were a direct effect of finer grain sizes and a precipitation lean matrix.
\end{abstract}




\section{INTRODUCTION}

Innovative methods for processing UDIMET alloy 718 have been evaluated to provide a technical solution to the cost concerns associated with large lot sizes and associated inventory requirements. With increased demands to reduce material inventories and lead times (where lead time is the time from when an order is obtained to when the order is delivered), it becomes very important to identify compatible processing routcs. Compatible processing routes permit the application of in-process inventory to multiple end products. This provides an opportunity to reduce lead time through the use of buffers ${ }^{1}$ without altering end product quality or integrity as indicated in Figure 1.

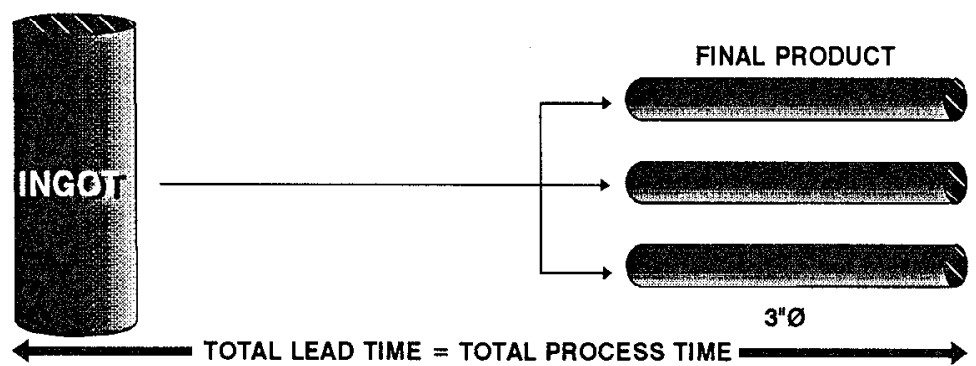

a) Incompatible Process Routes Require Each Final Part Be Produced from the same starting point.

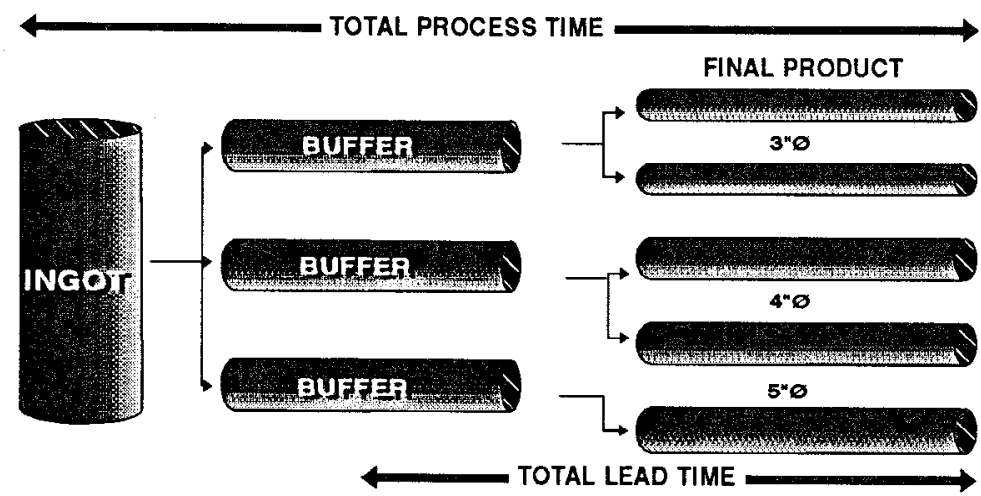

b) A Compatible Process Permits Multiple Applications be Met Using a Single Inventory.

Figure 1. The use of compatible process routes permits reduced lead times and smaller lot sizes when applying material from in process inventories or "buffers".

To the Metallurgical Engineer, establishing compatible thermomechanical processing routes for UDIMET alloy 718 can be particularly challenging since the final billet or bar microstructure and mechanical properties can be very dependent on 
controlling the process parameters of strain, strain rate and temperature. In this study, subscale compression testing was used to predict flow stresses and the microstructural response to various conversion conditions. Controlling parameters were established for delta processed billet material? and standard fine grain billet material of UDIMET alloy 718. Subsequent to the testing, the delta processed material (UDIMET alloy 718DP) was further processed to provide smaller diameter bar product of similar microstructure.

\section{EVALUATIONS}

\section{Material}

A $508 \mathrm{~mm}$ diameter vacuum induction melted plus vacuum arc remelted UDIMET alloy 718 ingot was forged to $140 \mathrm{~mm}$ diameter billet. During conversion, the ingot was sectioned to permit processing of one ingot section using delta processing techniques and the second ingot section using fine grain processing techniques. The chemistry of the material is presented in Table I.

TABLE I. THE COMPOSITION OF THE MATERIAL WAS TYPICAL UDIMET ALLOY 718

\begin{tabular}{||lcccccccccc||}
\hline \hline Heat & $\mathrm{C}$ & $\mathrm{Mn}$ & $\mathrm{S}$ & $\mathrm{Fe}$ & $\mathrm{Ni}$ & $\mathrm{Cr}$ & $\mathrm{Al}$ & $\mathrm{Ti}$ & $\mathrm{Mo}$ & $\mathrm{Cb}+\mathrm{Ta}$ \\
\hline 915030 & .03 & .06 & .0003 & 18 & 54 & 18 & .5 & 1.0 & 2.9 & 5.4 wt\% \\
\hline
\end{tabular}

The delta processed billet exhibited a uniform, very fine grain microstructure of ASTM $11-12$ as indicated in Figure 2. The standard conversion practice provided a grain size ASTM 10 with isolated coarser grains at the billet surface.

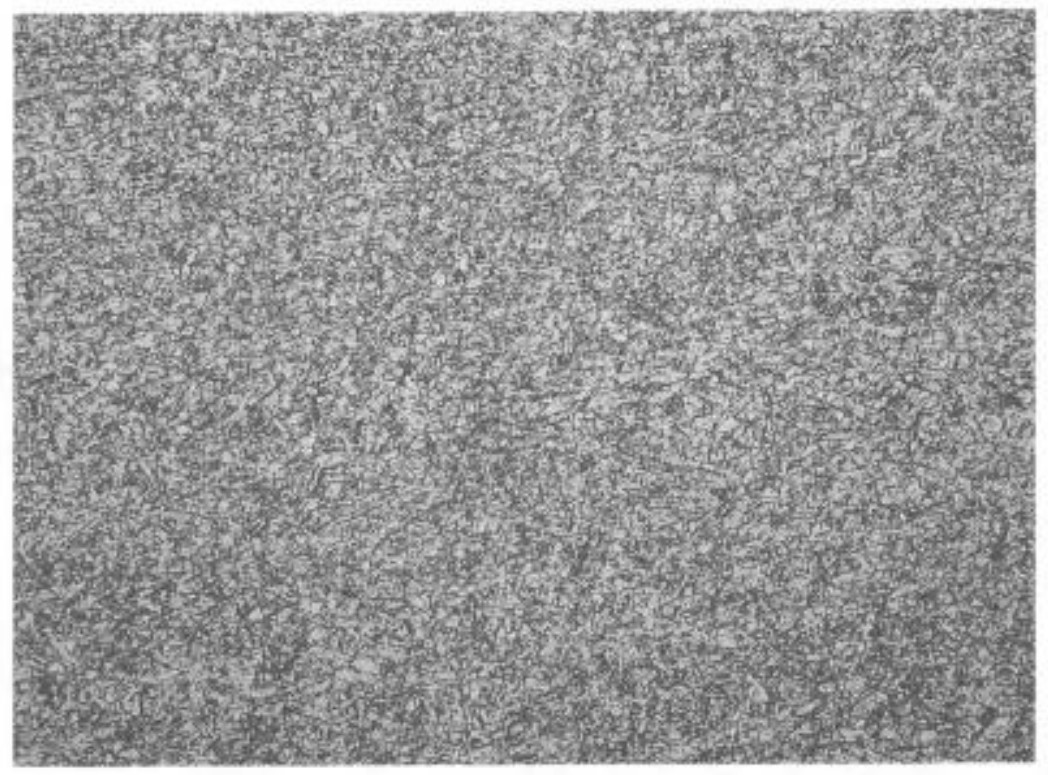

Figure 2. The $140 \mathrm{~mm}$ diameter delta processed material was considerably finer than the standard fine grain billet. 


\section{Sub-Scale Testing}

Hot Compression Testing (HCT) was performed on samples obtained directly from the billet material. compression testing was performed to provide flow stress and microstructural response for conversion temperatures in the range of $940^{\circ} \mathrm{C}$ to $1065^{\circ} \mathrm{C}$. Strain rates of $1.0 \mathrm{sec}^{-1}$ were utilized to simulate the roll reduction schedules. Total reduction was $50 \%$ using a cylindrical compression sample that was $10 \mathrm{~mm}$ in diameter and $15 \mathrm{~mm}$ high.

\section{Production Demonstration}

In this evaluation, demonstration was limited to the characterization of delta processed billet (after peeling to $127 \mathrm{~mm}$ diameter to remove the forged surface) and further reducing the 140 $\mathrm{mm}$ diameter delta processed billet to $76 \mathrm{~mm}$ diameter rolled bar. Characterization consisted of microstructural, macrostructural, mechanical and ultrasonic testing.

\section{RESULTS/DISCUSSION}

\section{Hot Compression Testing}

As indicated in Figure 3, the flow stress of the delta processed billet is considerably lower than conventional fine grain UDIMET alloy 718. This is most likely a result of the extremely fine grain starting microstructure and the presence of large spheroidized delta to support dynamic recrystallization. The reduced flow stress in delta processed UDIMET alloy 718 would suggest potential improvements in forgeability, die fill, and material utilization (tighter forge outlines) exist over the present fine grain UDIMET alloy 718 billet material.
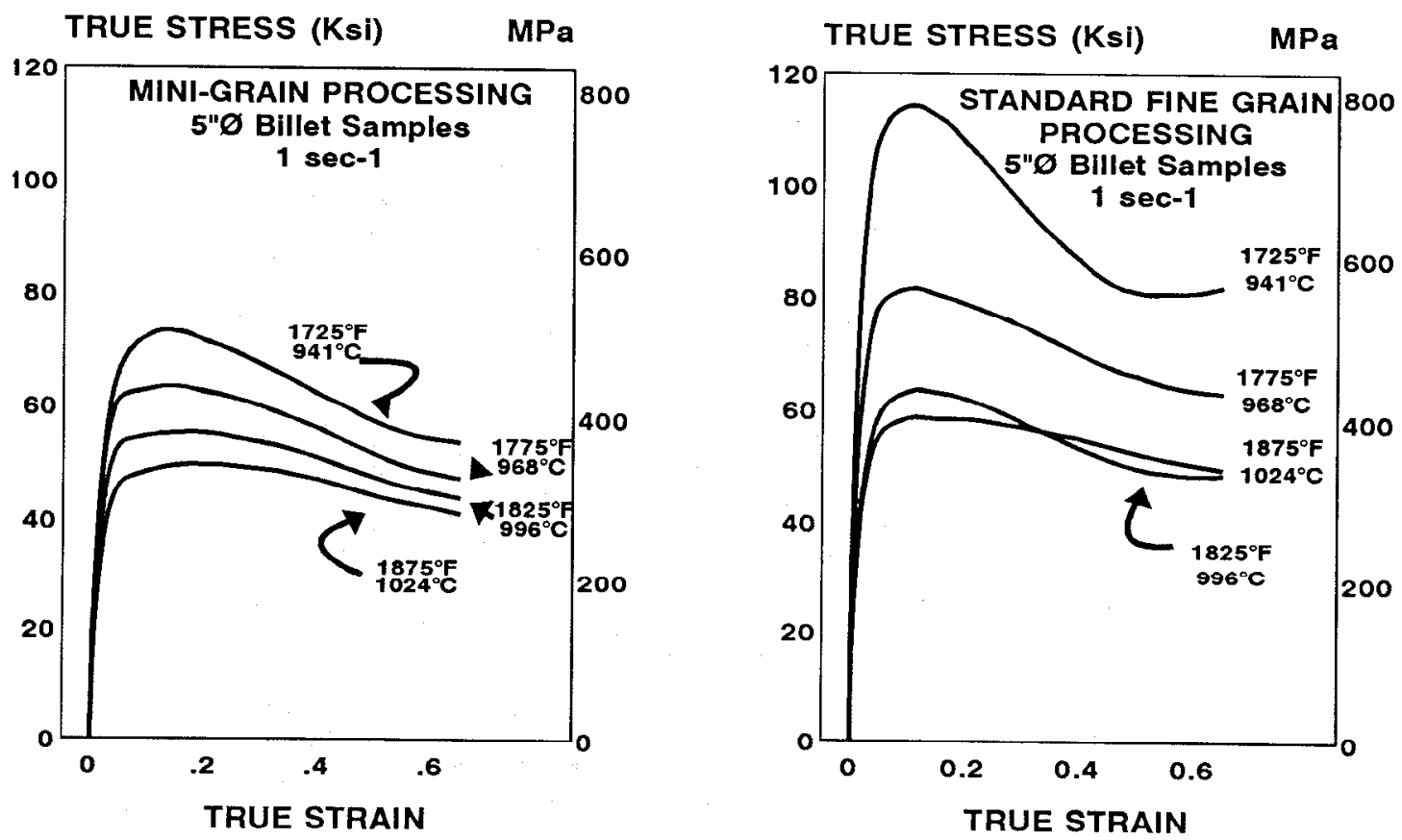

Figure 3. The flow stress of the delta processed billet was considerably less than standara fine grain material. 
Metallographic evaluations on the hot compression samples from the delta processed billet revealed a uniform very fine grain size (ASTM 12) at $968^{\circ} \mathrm{C}$ which increased uniformly with increasing test temperatures as indicated in Figure 4 .
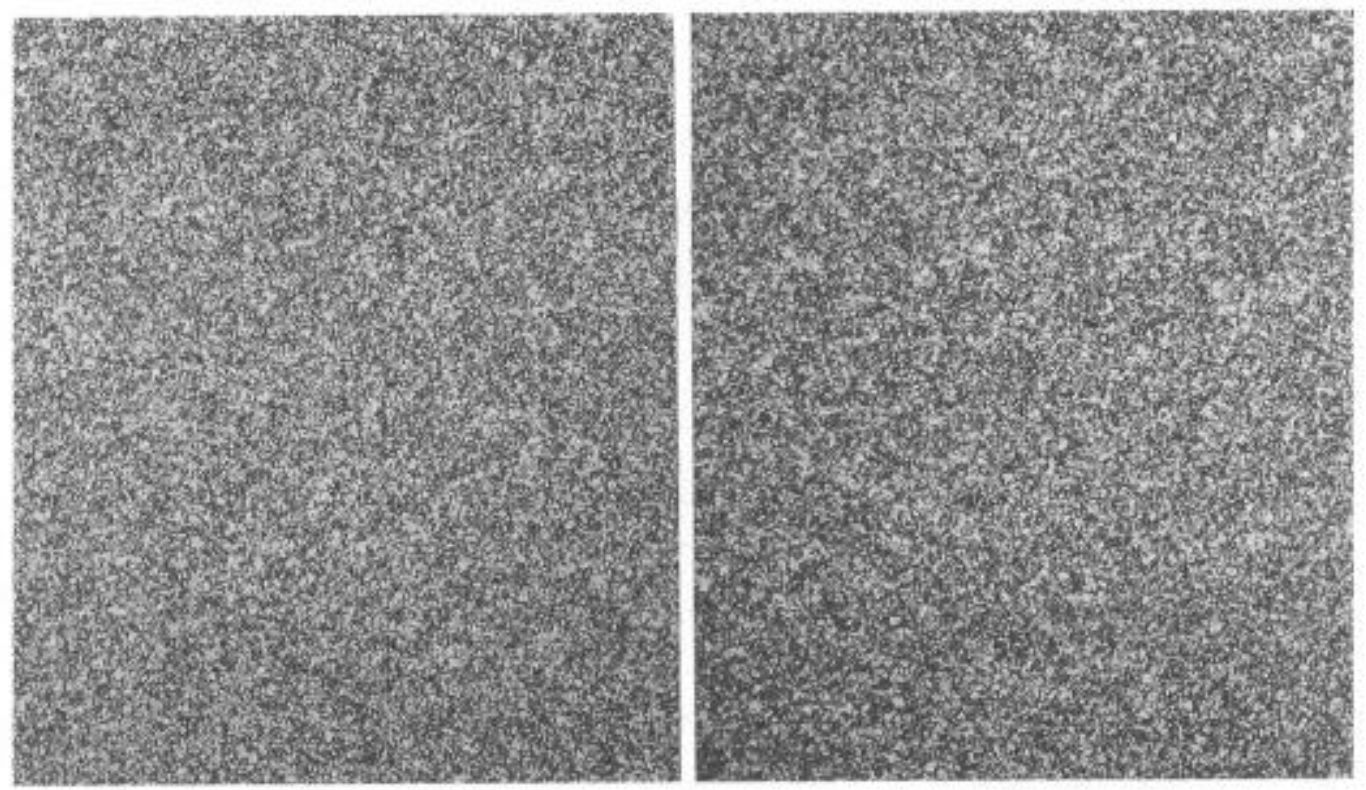

$968^{\circ} \mathrm{C}$

$996^{\circ} \mathrm{C}$
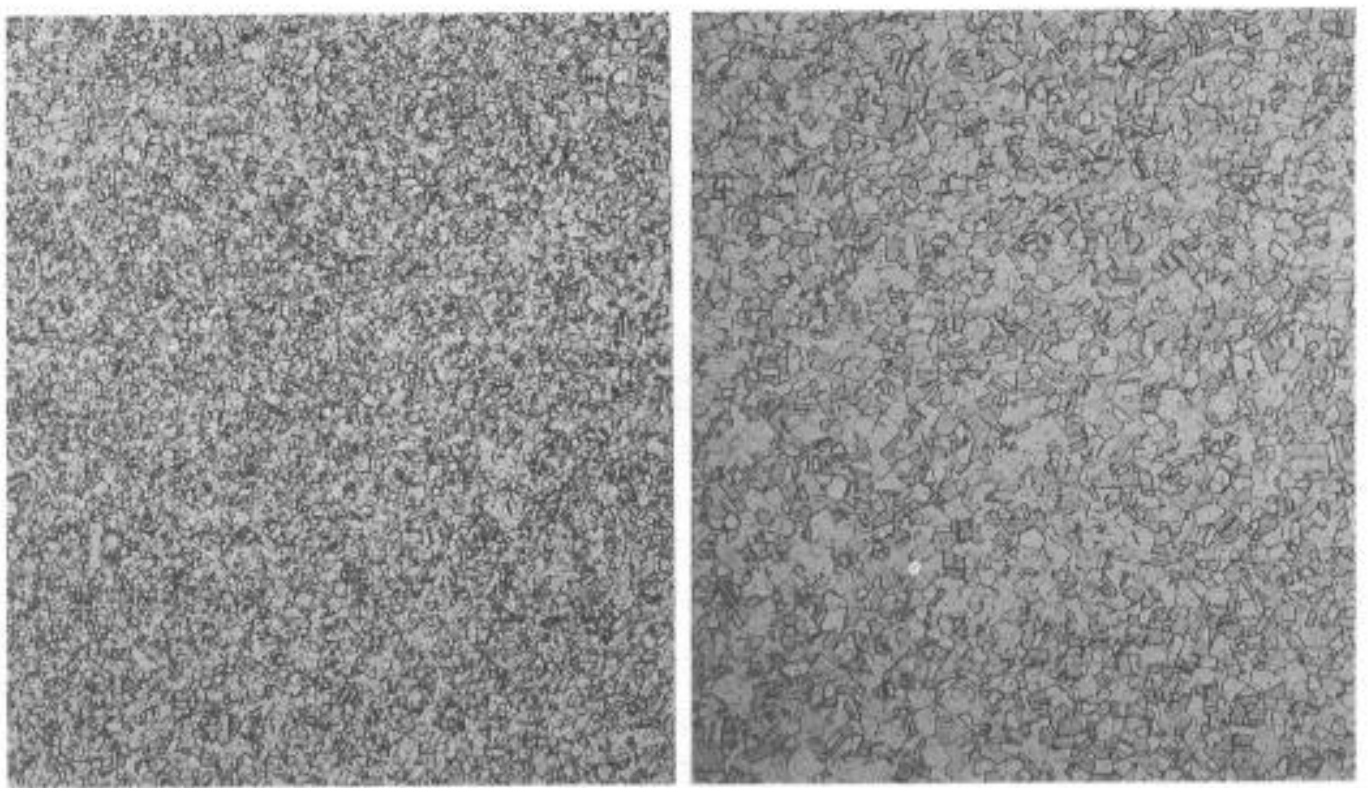

$1024^{\circ} \mathrm{C}$

Figure 4 . The fine grain billet microstructure was retained when testing at $968^{\circ} \mathrm{C}\left(\mathrm{T}, 1.0 \mathrm{sec}^{-1}, 50 \%\right.$ Reduction). 
The microstructure of the fine grain samples was maintained with a $940^{\circ} \mathrm{C}$ HCT temperature. However, grain coarsening was evident at $968^{\circ} \mathrm{C}$ which resulted in a necklace microstructure after reduction. At increasing temperatures, the fine necklace microstructure progressively coarsened as indicated in Figure 5.

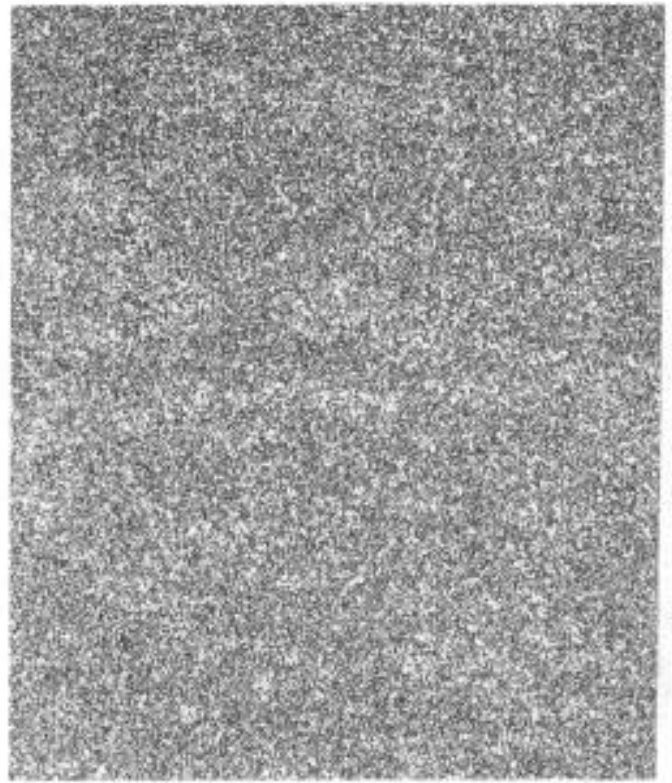

$968^{\circ} \mathrm{C}$

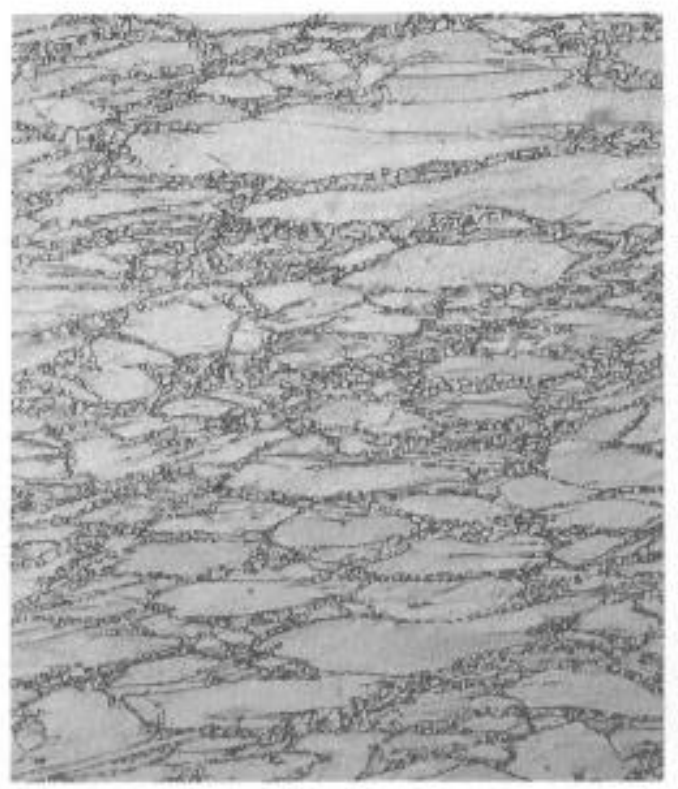

$1024^{\circ} \mathrm{C}$

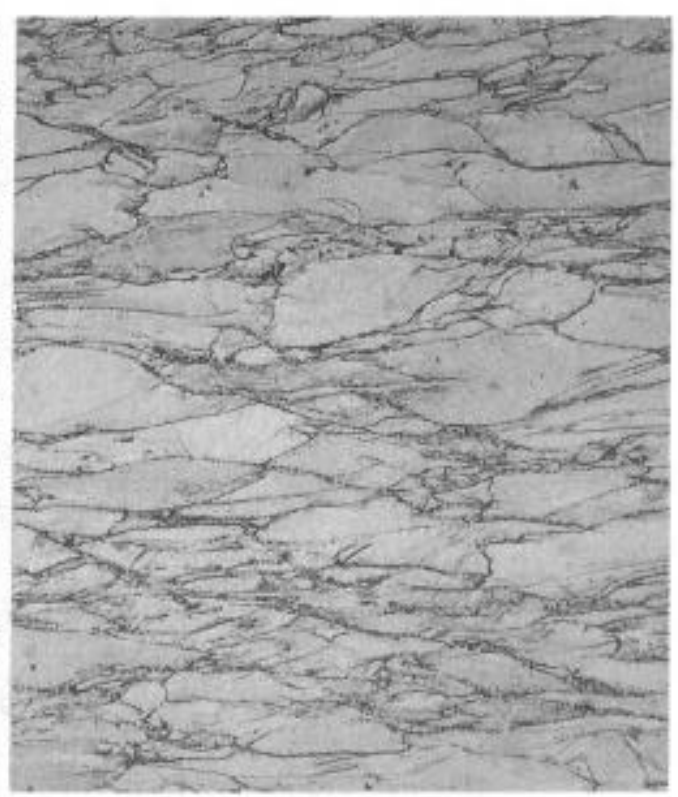

$996^{\circ} \mathrm{C}$

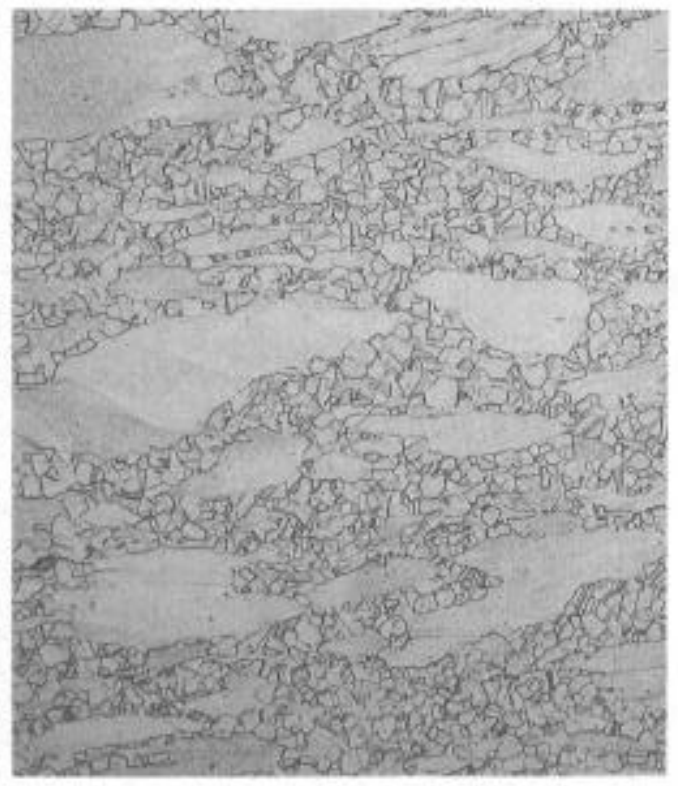

$996^{\circ} \mathrm{C}$

Figure 5. Hot compression samples from the fine grain billet process material exhibited a duplex microstructure at low temperatures. (T, $1.0 \mathrm{sec}^{-1}, 50 \%$ Reduction). 
The high flow stresses encountered when processing the fine grain billet at low temperatures to maintain the microstructural control would prohibit compatible rolling practices in that the reduction schedules would be restricted. Conversely, a significantly lower flow stress and retention of the delta processed billet microstructure at $968^{\circ} \mathrm{C}$ would permit further reductions to various sizes.

\section{Production Demonstration}

The $140 \mathrm{~mm}$ diameter delta processed billet was subsequently converted to $76 \mathrm{~mm}$ diameter bar product. The billet macrostructure, presented in Figure 6, exhibited a fine grain condition. The microstructure at $76 \mathrm{~mm}$ diameter (Figure 7) was a uniform ASTM 11-12 with a fine dispersion of spheroidized delta phase similar to the $140 \mathrm{~mm}$ diameter starting material.

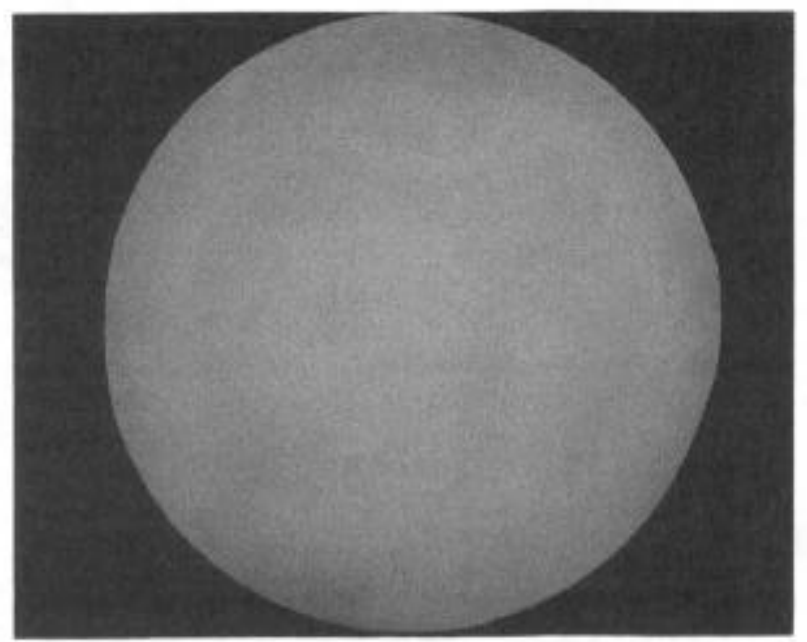

Figure 6. The $76 \mathrm{~mm}$ diameter bar exhibited a uniform macrostructure.
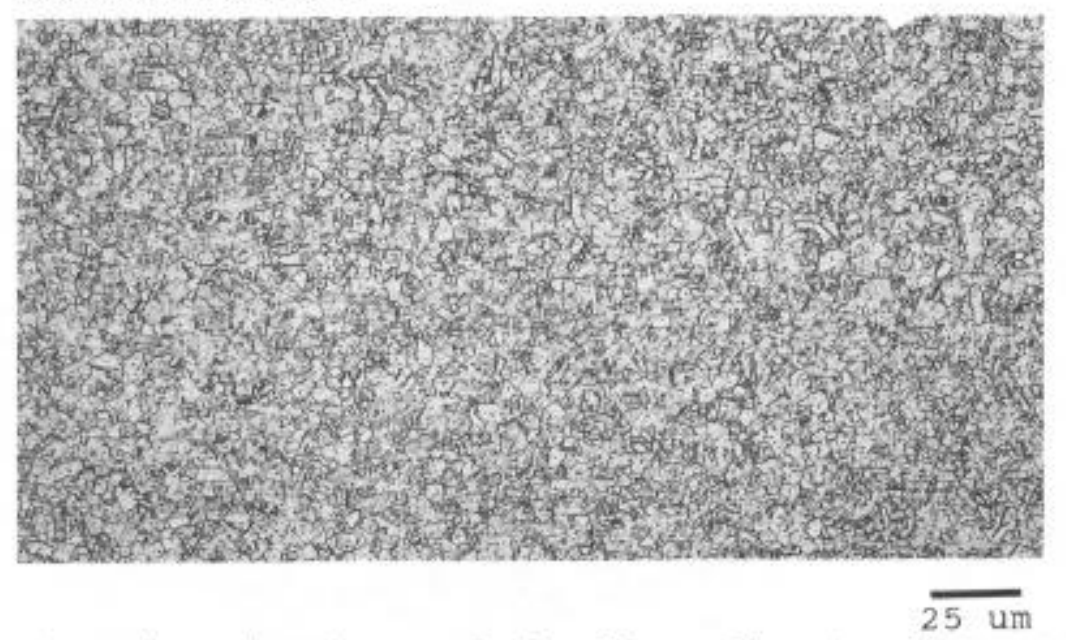

Figure 7. The microstructure of the $76 \mathrm{~mm}$ diameter bar was similar to the $140 \mathrm{~mm}$ diameter delta processed billet.

The process route is presently being utilized for compressor disk and shaft applications ${ }^{3}$. Through the use of a low temperature conversion sequence, both applications can be produced from a common inventory buffer to reduce lead time. 


\section{CONCLUSIONS}

1) When compared to standard fine grain processed material, the delta processed material exhibits a significantly lower flow stress at a strain rate of $1.0 \mathrm{sec}^{-1}$ and in the temperature range of $940^{\circ} \mathrm{C}$ to $1024^{\circ} \mathrm{C}$.

2) Delta processed billet can be further reduced to smaller stock sizes with no detrimental effect on the microstructure.

3) The delta process route provides an excellent example for reducing material lead times and process lot sizes with the use of a compatible process sequence and an inventory buffer.

\section{REFERENCES}

1. S. Shingo, A study of the Toyota Production system From an Industrial Engineering Viewpoint, Productivity Press, 1989, Cambridge, MA, pp. 29-32.

2. T. Banik, P.W. Keefe, G.E. Maurer and L. Petzold, "Ultra Fine Grain/Ultra Low Carbon 718", Superalloys 718, 625 and Various Derivatives, Proceedings of the International symposium June 23-26, 1991, pp. 913-924.

3. C. Ruiz, A. Obabueki, and K. Gillespie, "Fvaluation of the Microstructure and Mechanical Properties of Delta Processed Alloy 718", Superalloys 1992, Proceedings of Symposium Sponsored by TMS Seven springs International symposium Committee, ASM and ASME, September 20-24, 1992, p.34. 